\title{
Ekstraksi logam EMas/PeraK Dari Larutan BiJiH EMas/Perak Dengan Sistem PenYerapan Menggunakan Karbon AKTIF Batubara Sub-BItuminus (COALITE)
}

\author{
${ }^{1}$ Solihin dan ${ }^{2}$ Dono Guntoro \\ ${ }^{1,2}$ Prodi Teknik Pertambangan, Fakultas Teknik, Unisba, Bandung \\ e-mail: ${ }^{1}$ solihintambangunisba@gmail.com
}

\begin{abstract}
Abstrak. Salah satu metoda dalam rangka penganekaragaman (diversifikasi) pemanfaatan batubara adalah dijadikan karbon aktif. Hal ini dapat dilakukan karena batubara merupakan suatu material yang unsur utamanya adalah karbon (C) yang sangat diperlukan sebagai bahan baku pembuatan karbon aktif, sebagaimana bahan baku lainnya seperti tulang, biji kopi, tempurung kelapa, serbuk gergaji, kulit kacang dan lain-lain.Penelitian ini, mencoba membuat karbon aktif dengan bahan baku berasal dari batubara sub-bituminus yang telah dikarbon isas $i$ (coalite). Coalite tersebut kemudian diaktifasi pada temperatur $900^{\circ} \mathrm{C}$ (secara bertahap) pada kondisi tanpa oksigen yang kemudian dialirkan uap air. Batubara hasil aktifasi tersebut kemudian dicoba digunakan sebagai media penyerap logam emas/perak dalam larutan bijih emas sianida (AuCN), yang pada industri pertambangan proses ini sering disebut carbon in leah (CIL). Mengingat pemakaian karbon aktif dalam industri yang sangat beragam dan telah diakui keandalannya, penelitian ini diharapkan memberikan hasil, antara lain sebagai berikut:1. Coalite yang telah dikarbonisasi, diharapkan dapat dijadikan bahan baku pembuatan karbon aktif. 2. Coalite setelah diaktifasi menjadi karbon aktif, diharapkan dapat digunakan sebagai media penyerap logamemas/perak, yang saat ini masih diimport. Dari penelitian ini, diharapkan dapat diketahui besaran optimum karbon aktif (gram), waktu penyerapan (jam) dan ukuran butir karbon aktif batubara (mesh). Untuk mengetahui kandungan emasnya, larutan kaya hasil pelindian dianalisis dengan spektrofotometri serapan atom(SSA). Setelah diketahui adanya penyerapan logam emas/perak terhadap butiran karbon aktifbatubara baik sebelum ataupun setelah penyerapan, dilihat dengan scanning electron microscop (SEM).
\end{abstract}

Keyword: karbon aktif, ekstraksi, coalite dan penyerapan

\section{Pendahuluan}

Teknologi carbon in laech (CIL) dengan sistem pelindian menggunakan sianida (sianidasi) saat ini menjadi teknologi baku dalam pengolahan bijih emas. Pada awalnya, proses untuk memperoleh kembali (recovery) emas (Au) dan perak (Ag) dari bijihnya adalah dengan memanfaatkan sistem sementasi (pengendapan) serbuk seng ( $\mathrm{Zn}$ ), namun akhir-akhir ini proses konvensional tersebut sudah dianggap tidak efisien dan tidak selektif lagi, karena logam selain emas dan perak turut mengendap (Dayton, SH, 1987).

Ketidak selektifan memperoleh kembali emas dengan pengendapan, saat ini perhatian tertuju pada sistem penyerapan (adsorpsi) menggunakan karbon aktif yang dalam ekstraksi emas dan perak pada proses pengalohan bahan galian tambang disebut carbon in laech.

Karbon aktif pada proses CIL di atas, unsur utamanya dibentuk oleh karbon (C), sehingga bahan bakunya bisa digunakan batubara, hal ini karena batubara disusun oleh 
komponen utama karbon (C) sebagaimana bahan baku karbon aktif lainnya seperti tulang, biji kopi, tempurung kelapa, serbuk gergaji, kulit kacang dan lain-lain. Batubara di Indonesia saat ini pemanfaatannya masih relatif terbatas, terutama hanya sebagai bahan bakar pada pembangkit listrik tenaga uap (PLTU) dan bahan bakar pada industri semen, sedangkan menurut data Pusat Sumberdaya Geologi, Badan Geologi, KESDM (2014) sumberdayanya mencapai $\pm 124,80$ milyar ton dan cadanganya mencapai \pm 32,38 milyar ton. Dengan kondisi tersebut, maka penelitian ini mencoba membuat karbon aktif yang bahan bakunya berasal dari batubara sub-bituminus yang telah dikarbonisasi dan sering disebut coalite. Karbon aktif dengan bahan baku batubara tersebut kemudian digunakan untuk me-recovery (menyerap) logam emas dan perak dari bijihnya dalam bentuk larutan emas sianida $(\mathrm{AuCN})$.

Istilah yang umum untuk rumpun dari bahan yang mengandung karbon berlubang (berpori) disebut karbon aktif, tidak bisa diberikan ciri khusus dengan rumus yang berhubungan dengan struktur atau dengan analisis kimia (Mc. Daugall, G.J., 1991).

Kemampu-serapan dari karbon aktif yang berfungsi sebagai adsorbate, sangat dipengaruhi oleh terbentuknya pori - pori dari arang padat setelah melalui proses karbonisasi dan aktifasi. Daya serap antara adsorbate terhadap zat atau bahan yang diserap sebagai adsorbent, selain dipengaruhi oleh struktur, ukuran dan jumlah pori dari tiap butir karbon aktif, juga dipengaruhi oleh besarnya ukuran butir (mesh) serta banyaknya (berat) karbon aktif.

Struktur dan jumlah pori dari tiap butiran bubuk karbon aktif, diketahui sangat menentukan kemampu-serapan terhadap adsorbate, suatu saat struktur pori tersebut akan mengalami kejenuhan yang dipengaruhi oleh besarnya konsentrasi absorbate dan lamanya waktu kontak antara adsorbate dengan adsorbent.

\section{Metode Penelitian}

Metodologi penelitian yang digunakan adalah dengan menggunakan pendekatan deskriptif analisis yaitu suatu pendekatan dimana setelah data diperoleh, kemudian dilakukan perhitungan dan analisis dengan menggunakan rumus-rumus baku yang umum serta banyak digunakan.

Untuk memudahkan memperoleh data yang akan digunakan, dibahas dan diolah maka metodologi penelitian yang dilakukan adalah sbb:

a. Data sekunder, diperoleh dengan cara membaca buku referensi, jurnal, makalah hasil seminar atau hasil penelitian terdahulu yang berkaitan dengan topik penelitian ini.

b. Data primer, diperoleh dengan cara melakukan penelitian langsung di lapangan dan di laboratorium.

Penelitian ini merupakan tahun pertama dari rencana dua tahun, sehingga sebagaimana diketahui dan dapat dilihat pada Gambar 2.1 Bagan Alir Proses Adsorpsi bahwa pada tahap pertama ditujukan untuk melakukan kajian terhadap pembuatan karbon aktif yang bahan bakunya berasal dari batubara dengan spesifikasi karbon aktif ditujukan untuk memenuhi karbon aktif sebagai media penyerap (adsorpbent) pada proses ekstraksi logam emas/perak dari bijihnya. Pada tahap ke dua atau tahun ke dua, setelah diperolehnya karbon aktif dengan bahan baku berasal dari batubara adalah mengkaji atau mencoba pemakaian karbon aktif batubara tersebut pada proses ekstraksi 
logam emas/perak dari bijihnya, yang prosedur atau tahapan pekerjaannya adalah sebagaimana dapat dilihat pada Gambar 2.1.

\section{Hasil dan Pembahasan}

Sebagaimana program atau rencana penelitian yang diusulkan ke Kementrian Ristek dan Dikti, Dirjen Pembelajaran dan Kemahasiswaan, melalui Direktorat Penelitian dan Pengabdian Kepada Masyarakat (PPKM), yang secara diagram alir dapat dilihat pada Gambar 2.1. Penelitian disetujui dan dilaksanakan dalam dua tahun, dengan target tahun pertama yang ingin dicapai adalah pengkajian pembuatan karbon aktif dengan spesifikasi diharapkan dapat memenuhi persyaratan sebagai media adsorpsi untuk ekstraksi logam emas/perak dari bijihnya. Sehingga oleh karena itu, dalam makalah penelitian tahun ke satu ini, dibatasi hanya pada penelitian pengkajian pembuatan karbon aktif batubara dengan spesifikasi karbon aktif batubara untuk ekstraksi logam emas/perak, sedangkan terhadap penelitian karbon aktif batubara yang digunakan dalam ekstraksi logam emas/perak dari bijihnya akan dilakukan di tahun ke dua berikutnya.

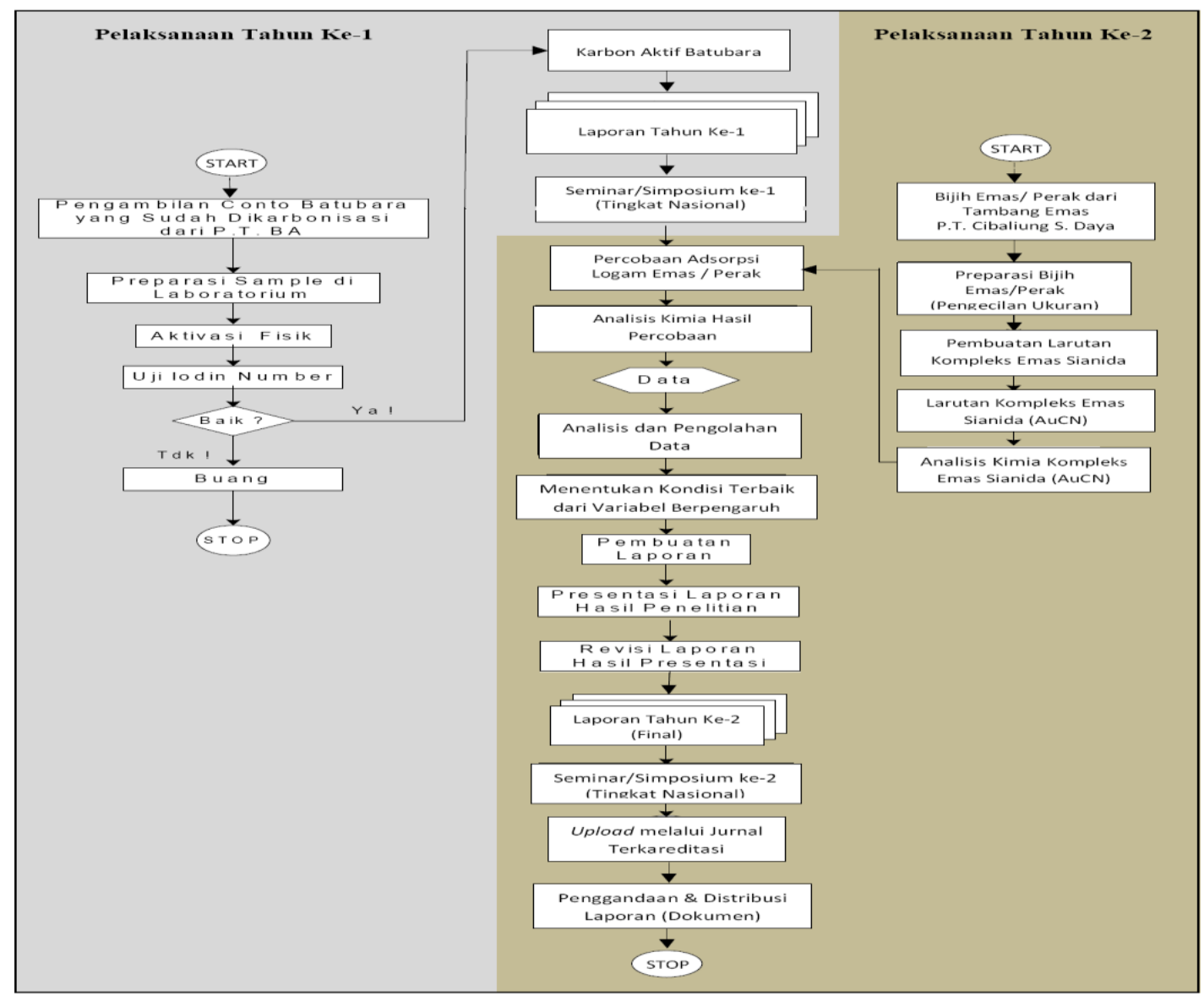

Gambar 2.1 Diagram Alir Percobaan Adsorpsi Logam Emas/Perak dengan Pelaksanaan Tahun Ke 1 dan 2 
Sebagai langkah atau pekerjaan awal di tahap atau tahun ke 1 ini yang dilakukan adalah pengadaan bahan baku karbon aktif yaitu batubara semi kokas yang berasal dari P.T. Bukit Asam, Tanjung Enim, Sumatera Selatan. Batubara ini juga merupakan bahan baku produk briket di P.T. Bukit Asam, Tanjung Enim yang sering disebut coalite sehingga tidak perlu melakukan karbonisasi dan tinggal langsung melakukan aktifasi baik secara fisika maupun kimia.

Ukuran bahan baku karbon aktif batubara coalite yang diperoleh dari P.T. Bukit Asam, Tanjung Enim, Sumatera Selatan masih berukuran kasar berkisar 0,5 - 2 CM, sedangkan karbon aktif batubara untuk proses ektraksi logam emas/perak dari bijihnya dipersyaratkan mempunyai ukuran $-10+16$ Mesh $(1-0,6 \mathrm{MM})$, sehingga oleh karenanya perlu adanya perlakuan pengecilan ukuran (communition). Selanjutnya terhadap produk ini, kemudian dilakukan aktifasi fisik dalam tungku (furnace) Carbolite yang dilengkapi dengan seperangkat alat pembangkit uap, thermo couple dan pengatur suhu (thermo start).

Tahun Ke 1 dan 2

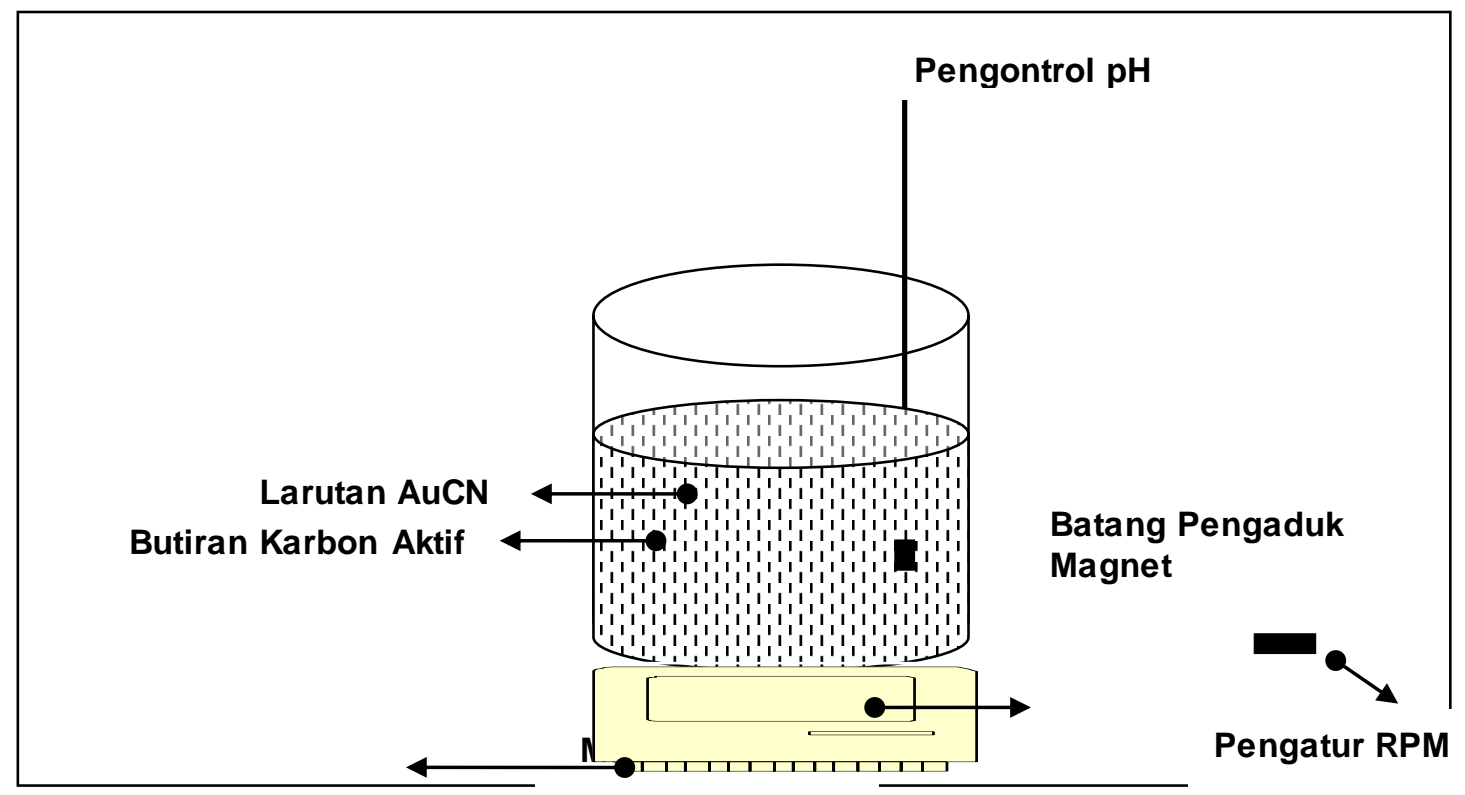

Gambar 2.2: Mekanisme Alat Adsorpsi Emas/ Perak

\section{Hasil dan Pembahasan}

Proses aktifasi fisik merupakan proses lanjutan dari karbonisasi agar pori-pori batubara (coalite) semakin terbuka. Reaksi aktifasi terbagi menjadi dua tahap. Tahap pertama berkurangnya keteraturan struktur karbon aktif akibat pemanasan, hasil ini membuka pori-pori yang masih tertutup. Tahap kedua yaitu karbon dari sistem ring aromatik mulai terbakar, yang menghasilkan keaktifan dan memperbanyak pori.

Ada dua macam proses aktifasi yaitu aktifasi secara fisika dan aktifasi secara kimia. Aktifasi kimia biasanya dilakukan pada bahan dasar kayu. Pada cara aktifasi kimia bahan dasarnya direndam dengan bahan kimia seperti asam fospor, seng klorida, asam sulfat, potassium thicyanat, hidroksida dan karbonat dari logam alkali serta klorida dari potassium, kalsium dan magnesium. Bahan-bahan kimia tersebut dapat meluruhkan 
senyawa-senyawa organik yang ada dalam bahan baku. Setelah itu bahan baku karbon aktif diaktifkan dengan menggunakan aliran uap air atau gas lain seperti CO2 atau N2 pada suhu pemanasan 700o C sampai 1000o C. Sehingga seolah-olah proses karbonisasi dilakukan secara bersama-sama dengan proses aktifasi. Pada aktifasi fisika terjadi pemisahan antara proses karbonisasi dan proses aktifasi (Hassler, 1974).

Proses aktifasi dengan steam menggunakan temperatur antara $700-1000^{\circ} \mathrm{C}$ tanpa oksigen, pada temperatur ini karbon sangat agresif dan akan mengurangi hasil oleh permukaan burn-off. Suatu kondisi proses aktifasi yang cocok akan menghasilkan jumlah pori yang banyak, sehingga total luas permukaan kisi-kisi (internal surface) akan meningkat dan tentu menambah daya serapnya.

Pada percobaan ini, aktifasi dilakukan pada berbagai fraksi dengan kecepatan pemanasan secara bertahap yaitu $400 \mathrm{C}$ per menit. Setelah mencapai temperatur 9000 $\mathrm{C}$, kemudian diturunkan sehingga mencapai temperatur $2500 \mathrm{C}$. Waktu yang diperlukan untuk 1 siklus pemanasan adalah \pm 8 jam.

Dari proses preparasi conto batubara coalite digiling dan diayak sehing diperoleh 5 (lima) fraksi ukuran butir yaitu $-4+10$ Mesh, $-10+16$ Mesh, $-16+28$ Mesh, $-28+48$ Mesh dan $-48+100$ Mesh dengan berat masing-masing 100 gram, batubara ini siap untuk dilakukan aktifasi. Setelah dilakukan aktifasi fisik diperoleh karbon aktif batubara dengan nilai iodin dan persen kehilangan berat sebagaimana dapat dilihat pada Tabel dan Gambar 3.1 di bawah ini.

Dengan melihat ukuran fraksi yang dihubungkan dengan presentase kehilangan berat dan setelah diuji nilai iodine number-nya, sebagaimana dapat dilihat pada Tabel dan Gambar 3.1 di atas, dapat disimpulkan bahwa:

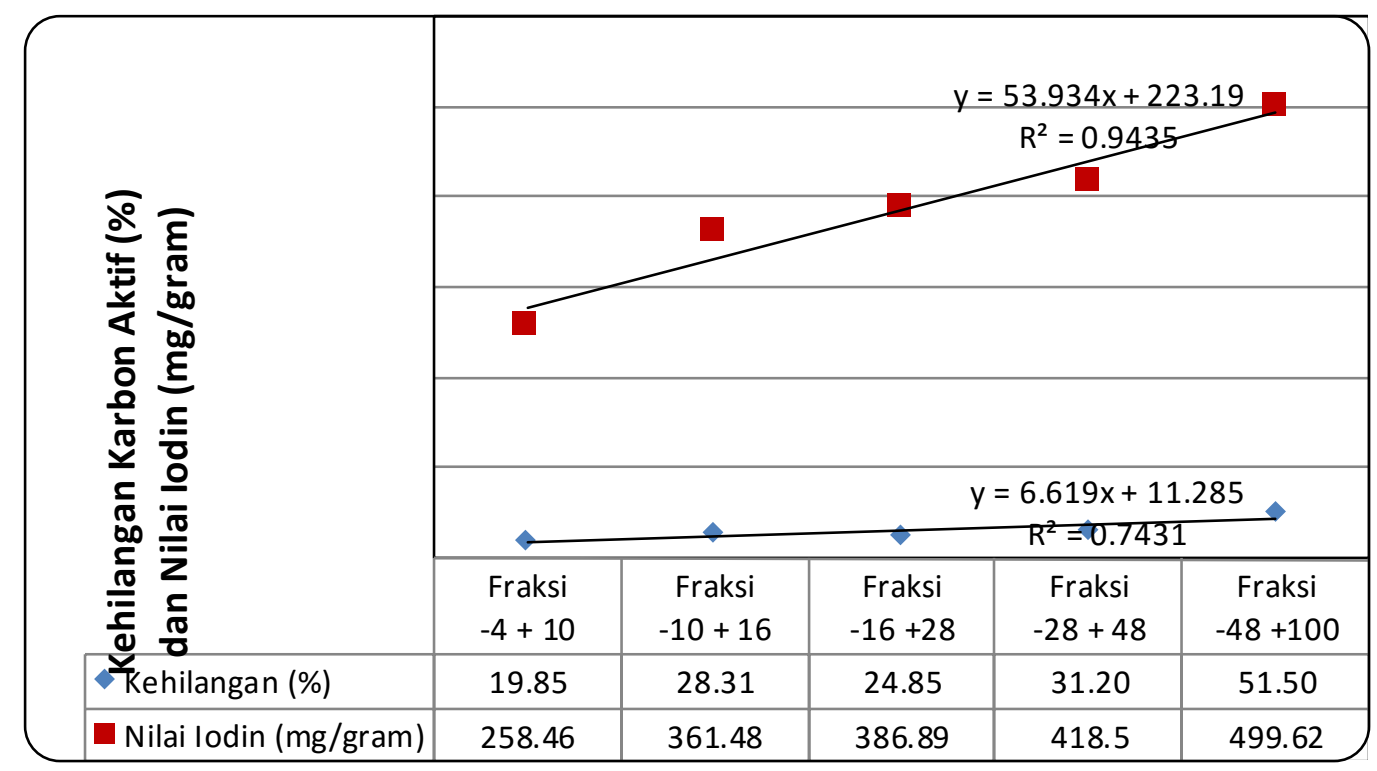

Gambar 3.1: Kurva Hasil Proses Aktifasi Fisik Coalite P.T. Bukit Asam, Tanjung Enim, Sumate ra Se latan pada Berbagai Fraksi

a. Batubara (coalite) yang berasal dari P.T. Bukit Asam, Tanjung Enim cukup baik dan sangat potensial untuk dikembangkan sebagai bahan baku karbon aktif, hal ini dapat dilihat dari nilai iodine yang relatif cukup besar yaitu 499,62, 
sedangkan karbon aktif yang berasal dari tempurung kelapa produksi P.T. Brataco besarnya adalah $330,96 \mathrm{mg} / \mathrm{gram}$.

b. Karbon aktif dengan nilai iodine seperti di atas memiliki daya serap yang relatif cukup baik dan tidak kalah nilainya bila dibandingkan karbon aktif yang dibuat dari tempurung kelapa yang sekarang banyak digunakan dalam industri.

c. Fraksi ukuran butir bahan baku karbon aktif (batubara/coalite) sangat berpengaruh terhadap kenaikan nilai iodine number yang mana fraksi makin halus memberikan nilai iodine yang makin besar tetapi perlu diperhatikan bahwa fraksi yang makin halus akan menaikkan juga presen kehilangan berat karbon saat proses aktifasi.

Sebagaimana diketahui bahwa karbon aktif import yang umum digunakan dalam proses CIL mempunyai ukuran butir dengan fraksi -10+16 mesh serta nilai iodin pada kisaran 1.050 - $1.150 \mathrm{mg} / \mathrm{gr}$. Bila dilihat pada Gambar 3.1 tersebut di atas, untuk fraksi -10+16 mesh mempunyai nilai iodine 386,89 mg/gr, maka oleh karena itu masih cukup jauh dari target yang dipersyaratkan. Dalam upaya pencapaian nilai iodin pada kisaran 1.050 - $1.150 \mathrm{mg} / \mathrm{gr}$ sesuai dengan yang direkomendasikan karbon aktif untuk proses CIL, maka dalam penelitian ini aktifasi dicoba divariasikan antara fraksi terhadap waktu pemanasan puncak 60, 120 dan 180 menit, serta temperatur pemanasan puncak 700, 800 dan 9000 C, kemudian diuji nilai iodinnya sehingga hasilnya dapat dilihat pada Tabel dan Gambar 3.2 sampai dengan 3.4 di bawah ini.

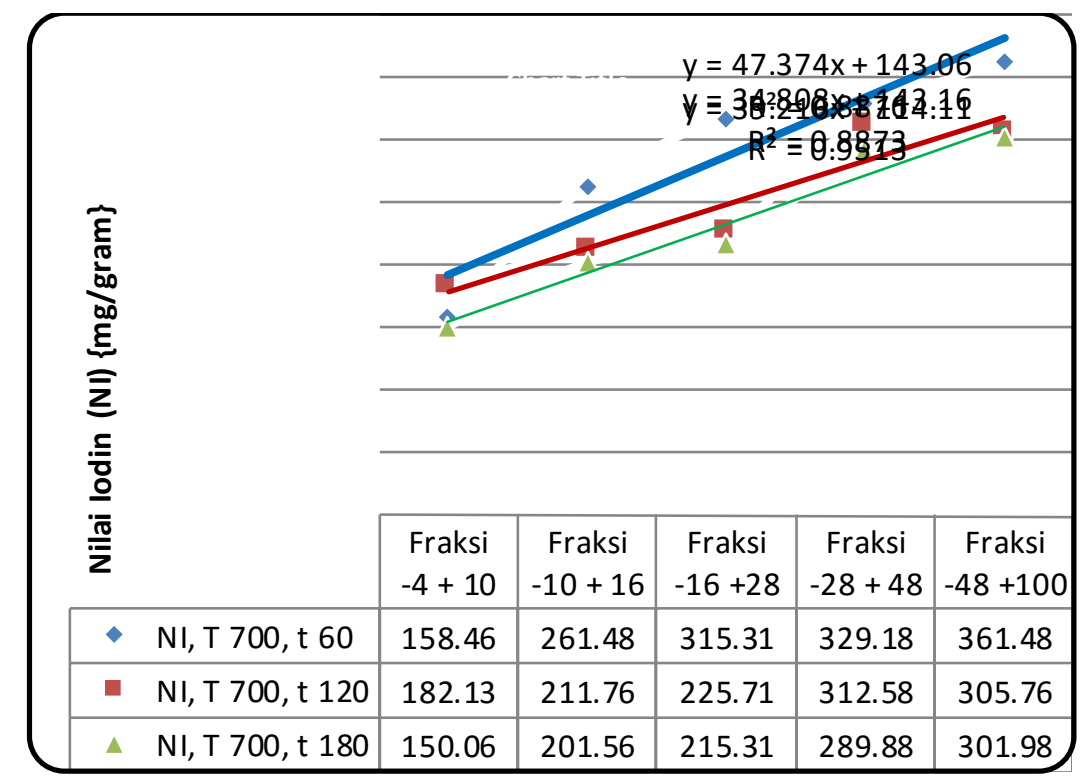

Gambar 3.2: Kurva Pengaruh Fraksi Ukuran Butir Terhadap Nilai Iodine dari Karbon Aktif Hasil Proses Aktifasi Fisik dengan Kondisi Temperatur Pemanasan 7000Cdan Waktu Pemanasan $\mathbf{t}=60$, 120 dan 180 Menit 


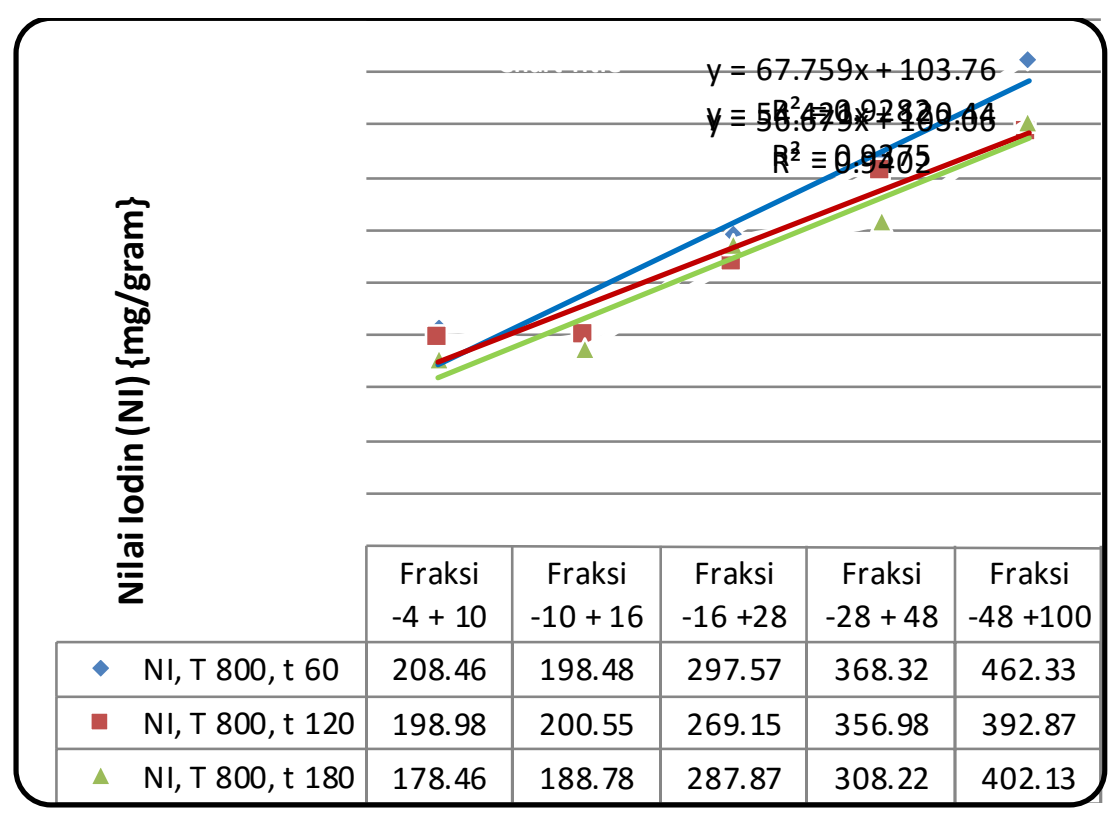

Gambar 3.3: Kurva Pengaruh Fraksi Ukuran B utir Terhadap Nilai Iodine dari Karbon Aktif Hasil Pros es Aktifasi Fisik dengan Kondisi Temperatur Pemanasan 8000C dan Waktu Pemanasan $\mathrm{t}=60,120$ dan 180 Menit

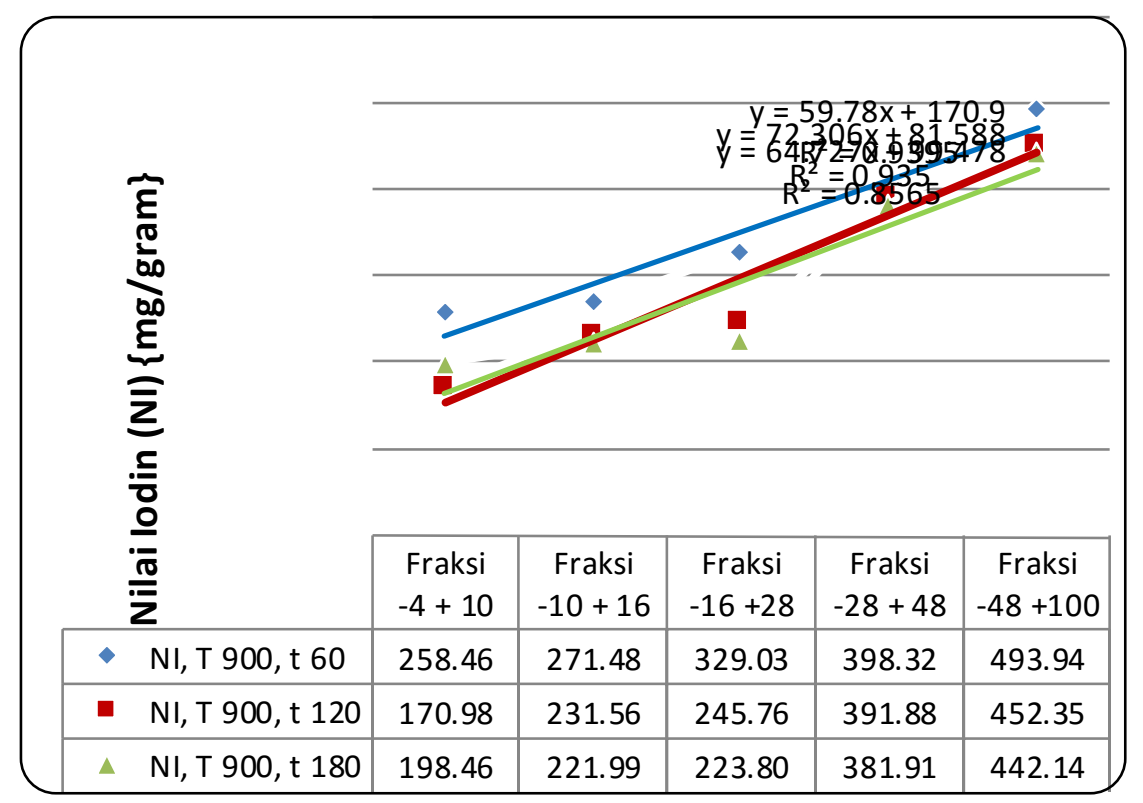

Gambar 3.4 Kurva Pengaruh Fraksi Ukuran Butir Terhadap Nilai Iodine dari Karbon Aktif Hasil Proses Aktifasi Fisik dengan Kondisi Temperatur Pemanasan 9000C dan

Waktu Pemanasan $\mathrm{t}=60,120$ dan 180 Menit

Bila dilihat dan dibandingkan antara Tabel atau Gambar 3.2 sampai dengan 3.4 dapat disimpulkan bahwa:

1) Pengaruh fraksi ukuran butir terhadap nilai iodine dari karbon aktif hasil proses aktifasi fisik sangat signifikan hal ini dapat dilihat bahwa makin halus ukuran butir bahan karbon aktif (coalite) nilai iodin makin besar, hal ini dapat dilihat dari kurva yang semakin naik. 
2) Di antara waktu pemanasan dan temperatur dari masing-masing fraksi, nilai iodin terbesar diperoleh pada temperatur pemanasan $9000 \mathrm{C}$ dengan waktu pemanasan puncak ditahan selama $t=60$ menit, meskipun tetap nilai iodin yang diperoleh tidak bias mencapai target karbon aktif yang dipersyaratkan untuk proses CIL sebagaimana karbon aktif import.

Dengan kondisi sebagaimana dijelaskan di atas, maka untuk mensiasati hal tersebut, kami memperoleh informasi dari hasil penelitian yang berbeda dengan bahan baku yang sama yaitu batubara (coalite) dari P.T. Bukit Asam, Tanjung Enim, Sumatera Selatan meskipun tidak bisa mencapai nilai iodin kisaran $1.050-1.150 \mathrm{mg} / \mathrm{gr}$ namun nilainya sudah mendekati yaitu antara 765 sampai dengan $1.004 \mathrm{mg} / \mathrm{gr}$.

Sebagai gambaran, bagaimana kondisi karbon aktif baik sebelum dan setelah proses aktifasi yang siap digunakan untuk proses CIL, pada Gambar 3.5 di bawah ini dapat dilihat hasil foto hasil scanning electron microscop (SEM).

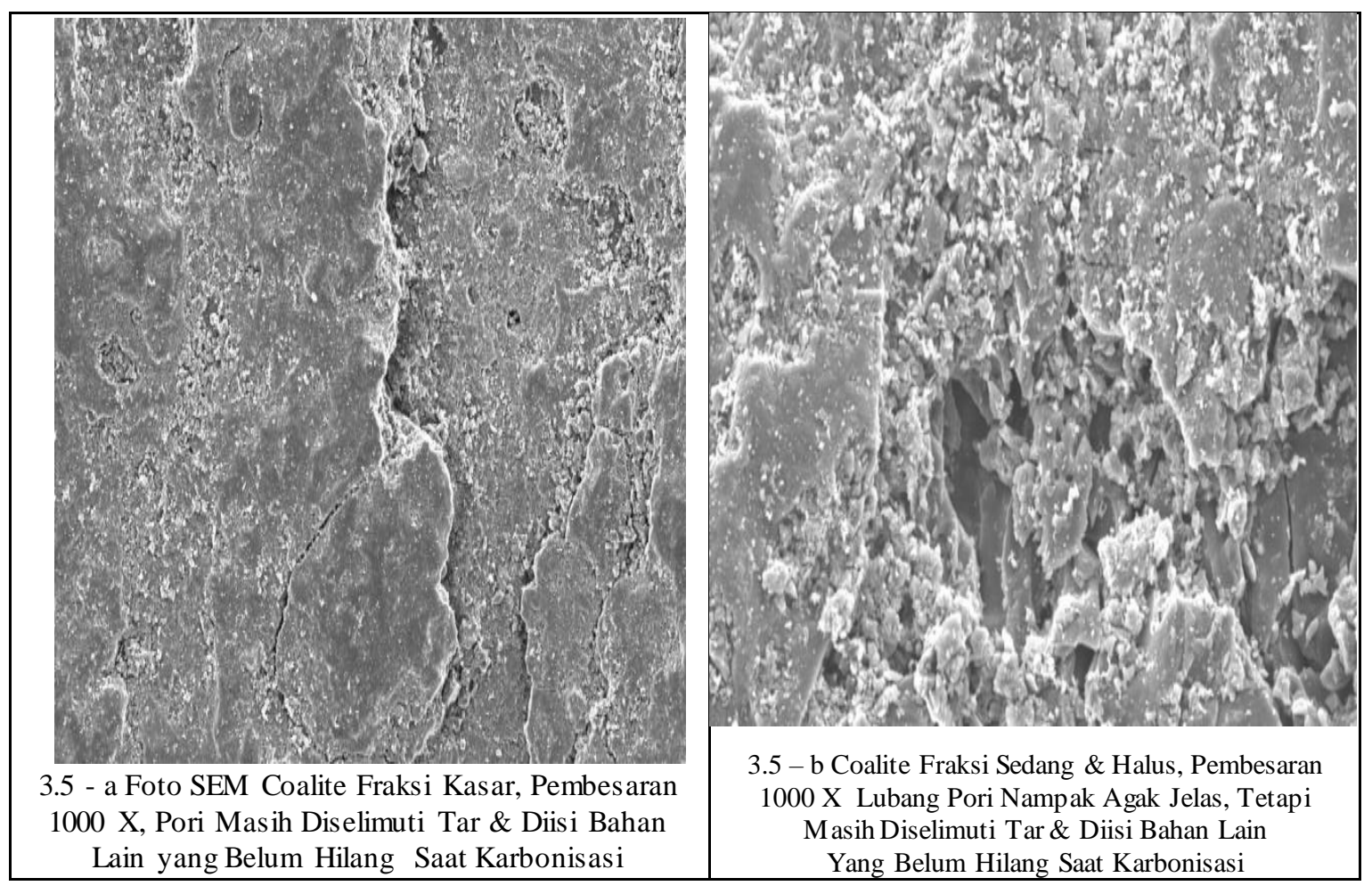




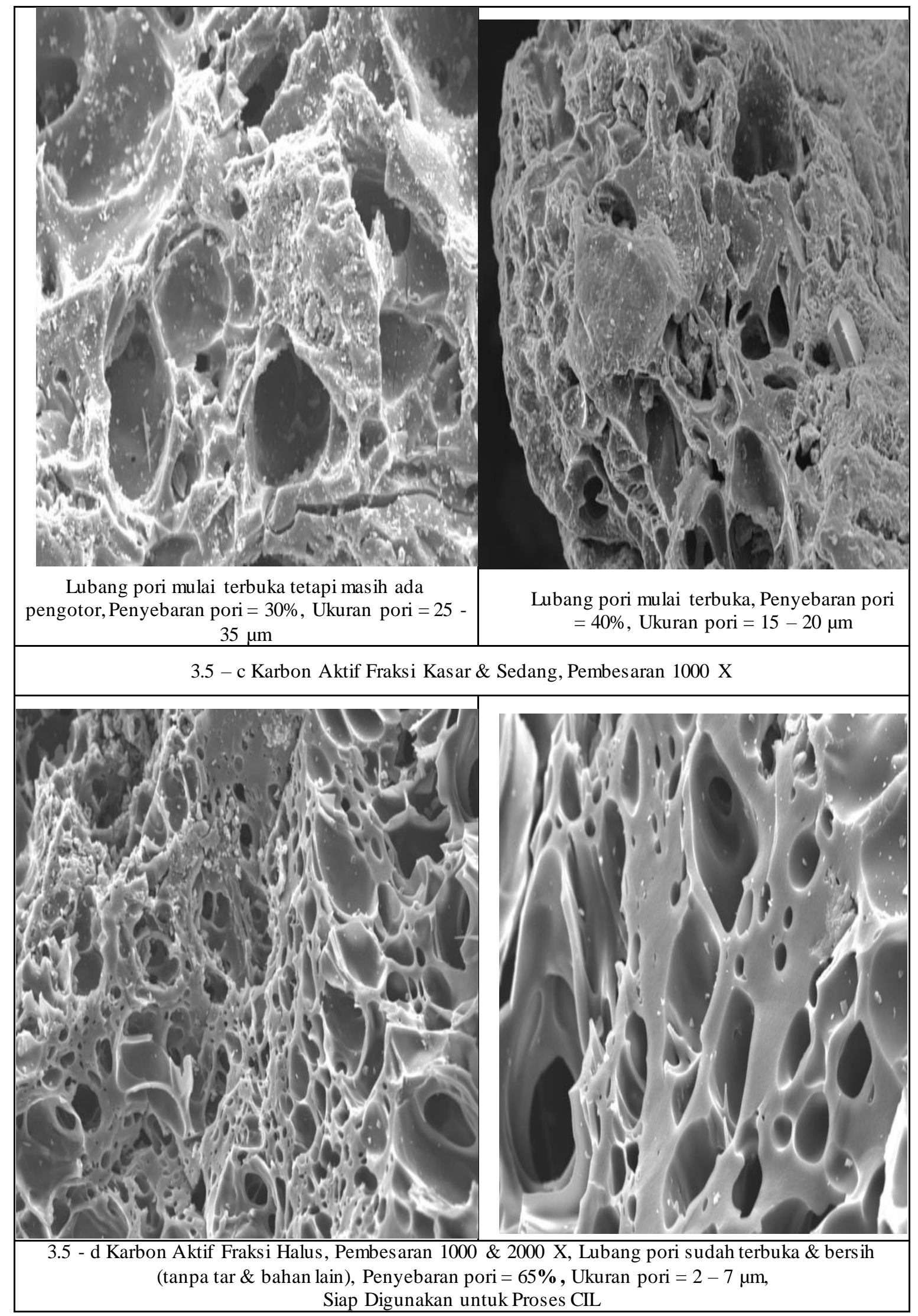




\section{Kesimpulan}

Dari hasil pengamatan, percobaan terhadap penelitian ini dapat dibuat kesimpulan sebagai berikut:

1) Batubara (coalite) yang berasal dari P.T. Bukit Asam, Tanjung Enim cukup baik dan sangat potensial untuk dikembangkan sebagai bahan baku karbon aktif, hal ini dapat dilihat dari nilai iodine yang relatif cukup besar yaitu 499,62, sedangkan karbon aktif yang berasal dari tempurung kelapa produksi P.T. Brataco besarnya adalah $330,96 \mathrm{mg} / \mathrm{gram}$.

2) Karbon aktif dengan nilai iodine seperti di atas memiliki daya serap yang relatif cukup baik dan tidak kalah nilainya bila dibandingkan karbon aktif yang dibuat dari tempurung kelapa yang sekarang banyak digunakan dalam industri.

3) Fraksi ukuran butir bahan baku karbon aktif (batubara/coalite) sangat berpengaruh terhadap kenaikan nilai iodine number yang mana fraksi makin halus memberikan nilai iodine yang makin besar tetapi perlu diperhatikan bahwa fraksi yang makin halus akan menaikkan juga presen kehilangan berat karbon saat proses aktifasi

Di antara waktu pemanasan dan temperatur dari masing-masing fraksi, nilai iodin terbesar diperoleh pada temperatur pemanasan $9000 \mathrm{C}$ dengan waktu pemanasan puncak ditahan selama $t=60$ menit, meskipun tetap nilai iodin yang diperoleh tidak bias mencapai target karbon aktif yang dipersyaratkan untuk proses CIL sebagaimana karbon aktif import.

\section{Daftar Pustaka}

Dayton, S.H, 1987, "Gold Processing Update”, E\& Mj, V. 188. No. 6 (June) pp. 25-29

Mc. Dougall, G.J, 1991, The Phisical Nature and Manufacture of Activated Carbon, J S. Afr. Inst. Min. Metall, Vol. 91, No. 4 (April), pp. 109-12.

Milansmisek, 1970, "Manufacture of active carbon", Applications of active carbon Chapters 2 and 5 in Active Carbon Milan Smisek and Slovoj Cerny, Editors Elsevier Amsterdam-London-New York pp 42 \& 256-257.

Rumbino, Yusuf, 2002, "Kajian Kemungkinan Penggunaan Karbon Aktif Batubara Bayah Sebagai Media Penyerap Logam $\mathrm{Cd}, \mathrm{Cu}$ dan Mn", Tesis Bidang Khusus Teknologi Pemanfaatan Batubara, Program Pasca Sarjana Rekayasa Pertambangan, Institut Teknologi Bandung

Van Vliet, B.M., 1985, Comparative Efficacy of extractive and thermal regeneration of activated carbon, Proceeding of the 14th IWSA, International Congress, Zurich.

Calvin Karo Kari Gurusinga, 2013, Peta Sebaran Lokasi Batubara Indonesia, PSDG, Badan Geologi, KESDM.

AWWA B 604 (American Water Works Association B604-12 Granular Activated Carbon edition 2012) 